\title{
Application of Decision Support System during the Emergency Exercises for Nuclear Emergency Management
}

\author{
S.K.Pawar, C.V.Srinivas, B.Venkatraman, J.Bhavani
}

\begin{abstract}
In India, two independent decision support system (DSS) systems are developed and implemented at NAPS (Narora Atomic Power Station) and MAPS (Madras Atomic Power Station) sites for emergency response. The simulation results of the DSS systems guides in identification of emergency zones and distances and implementation of the protective actions. This paper describes application / testing of the three decision support systems developed by IGCAR, NPCIL and SRI (AERB) for dose projections and decision on the implementation of the protective action in the public domain during the recently conducted emergency exercise at NPP site. Thus three DSS systems developed in India were applied to perform atmospheric dispersion and dose assessment in public domain around the nuclear power plants (NPPs) during the recent emergency exercise. The hypothetical accident scenario was considered for the exercise. The source term estimated based on plant parameters and pre calculated source term for large number of accident scenarios was used during the exercise. The results of the assessments by using these Decision support systems were presented to the decision makers for recommendation and implementation of protective actions such as evacuation, sheltering, $\mathrm{KIO}_{3}$ distribution, contamination control etc. The Numerical Weather Forecast model was used for the area around the NPP to produce the meteorological parameters that were further used by these DSS system. Predictive assessments of the radiological situation in the vicinity of the NPP site was performed during emergency exercise with various source terms. Taking into account the high uncertainties in the source term estimation and inputs to the simulation models, the simulated results from these three DSS show a reasonable agreement. The study demonstrated the utility of DSS systems for the assessment of the radiological consequences of hypothetical nuclear accidents during the emergency exercises at different NPP sites. The experience gained in using the DSS systems for operational application to the Indian NPPs will be further used by the exercise planners and developers to improve the system continuously and their adaptation to all NPP sites in India.
\end{abstract}

Keywords: Atmospheric dispersion, dose projection, DSS, hypothetical nuclear accident, protective actions, source term.

\section{INTRODUCTION}

Nuclear power plants in India are sited, designed, constructed and operated with highest priority to nuclear safety. The concept of defense-in-depth (five levels) is adopted to meet the safety objectives. These defenses help to reduce both the probability and consequences of nuclear accidents. Further, to address those events of small probability which have a potential to affect safety of plant personnel, public and environment a detailed emergency preparedness and response becomes necessary. Emergency preparedness is 5 th level in the defence in depth concept. The emergency preparedness and response plan at each NPP site includes the emergency response organization, their responsibilities and action plan, guidelines for evaluation of emergencies including source term and radiological impact, guidelines for mitigatory and protective actions, resources and facilities, communication system and coordination mechanism within all response organizations.

The goals of emergency management are to regain control of the situation and to mitigate consequences, avoid severe deterministic effects, reduce the risk of stochastic effects, mitigate non-radiological consequences, prepare for the resumption of normal social and economic activity. For effective implementation of protective actions, the area around the site is divided into emergency planning zones and distances. These zones and distances provide a basic geographic framework for decision making on implementing protective measures as part of a graded response in the event of an emergency. Up-on declaration of off-site emergency, various protective and response actions are taken promptly using generic criteria which is based on projected dose. A Decision Support System framework based on Weather Prediction and Atmospheric Dispersion models along with source term inputs is used for calculating the projected doses in the public domain which form an important input in formulating various response actions. The set of response

Revised Manuscript Received on October 25, 2019

* Correspondence Author

S.K.Pawar*, Directorate of Radiation Protection and Environment, AERB, Mumbai, India and Research Scholar, Sathyabama Institute of Science and Technology, Chennai, India.shivajikpawar@gmail.com.

C.V.Srinivas, Health Safety and Environment Group, IGCAR, Kalpakkam, India.cvsri@igcar.gov.in.

B.Venkatraman, Health Safety and Environment Group, IGCAR, Kalpakkam, India. bvenkat@igcar.gov.in.

J.Bhavani, VIT Business School, Vellore Institute of Technology, Chennai Campus, Chennai. drjbhavani2013@gmail.com. 
and protective actions required to be taken during emergency include: assessment of emergency, classification and declaration of emergency, onsite and off-site notification, activation of emergency response organizations, radiological monitoring within site area and off-site area, mitigatory action to control the radioactivity release, warning and advice, traffic control \& diversion, sheltering, prophylactics distribution, evacuation, relocation, decontamination of individuals, food and drinking water control, medical management of exposed people and protection of international trade and commercial interests. The process of implementation of optimized protective actions should result in more good than harm. The offsite EPR plans are implemented by the District Disaster Management Authorities with the technical support from the plant management and Crisis Management Group (CMG, DAE).

In India, two independent DSS systems are developed and implemented at NAPS and MAPS sites for emergency response. The simulation results of the DSS systems guide in identification of emergency zones and their spatial distance range for implementation of the protective actions. This paper describes application / testing of the three decision support systems developed by IGCAR (ONERS-Decision Support System), NPCIL (Real time Online Decision Support System (RO_DSS)) and SRI-AERB (Dose projection model / Atmospheric dispersion model) for dose projections and decision on the implementation of the protective action in the public domain during the recently conducted emergency exercise at NPP site.

\section{CONDUCT OF OFF-SITE EMERGENCY EXERCISE AT NPP SITE}

Off-site emergency exercise is conducted once in every two years at all nuclear power plant sites to meet regulatory requirement for maintaining a high level of emergency preparedness. A well-documented off-site emergency preparedness and response plan exists at each NPP site and with district authorities in which NPP is located. Recently such exercise was conducted at RAPS RR site in Dec. 2018 to provide unique insight in to the state of preparedness of emergency response organizations and are the basis for continued improvement program for the overall emergency response infrastructure.

\section{A. Accident Scenario}

The postulated accident scenario considered during the exercise was loss of coolant accident (LOCA) with further progression of loss of emergency core cooling system (ECCS), loss of moderator cooling and containment leakage in unit-3. The pressure inside the containment was assumed to reach the containment leak pressure and the release of large quantities of radionuclides to the atmosphere was occurred. After the containment breach, radionuclide release to the atmosphere decreased exponentially and completely stopped on next day.

\section{B. Goal of Emergency Exercise}

The goal of emergency preparedness is to ensure that an adequate capability is in place within the operating organization, district authorities other responsible organizations for an effective management of nuclear or radiological emergency. The objectives of the emergency exercise are to strengthen (a) early phase decision making, (b) integrated and coordinated emergency management response (c) ) evaluation of source term (d) use of decision support systems for dispersion assessment, dose assessment and dose projection (e) identification of the affected sector (protective action zones and distances) (f) implementation of protection strategy in public domain (g) analytical capabilities for projected dose assessment (h) Demonstrate environmental monitoring in the affected area and (h) prognosis of emergency situation.

\section{Response Organizations for Emergency Management}

All the response organizations stipulated in the approved EPR plan participated in the command and control integrated off-site emergency exercise. The response organizations involved in the exercise were plant management, district authorities, NPCIL HQ, CMG-DAE, NDRF of MHA, AERB, NDMA and state authorities.

\section{Response Activities for Emergency Management}

All the response activities as per preparedness plan was carried out during the exercise. This paper focuses on the application of DSS during the exercise for the management of hypothetical nuclear emergency. During the exercise analytical capability of the three DSS systems of IGCAR, NPCIL and SRI-AERB was tested. Analytical response groups used DSS and monitored the plant parameters, analysed the emergency situation, assessed the radioactive source term, predicted radiological parameters and dose assessment, generated the protective action recommendations for public protection and analysed the radiological impact by using actual \& predicted environment and meteorological conditions. Decision support system (DSS) worked in real time mode, predictions for radioactive concentration, inhalation dose, ingestion dose and whole body dose were done and affected area according to prevailing meteorological conditions were identified. Protective actions recommendations (PAR) were made by the site emergency director (SED) to district authorities based on projected dose simulated by DSS during urgent phase of emergency and by emergency response director (ERD, CMG-DAE) based on projected dose estimated by using actual measurement in affected areas during the early phase.

\section{ADAPTAITON OF THE DECISION SUPPORT SYSTEMS TO NPP SITE FOR EMERGENCY EXERCISES}

The three decision support systems developed by IGCAR, NPCIL and SRI (AERB) for dose projections and decision on the implementation of the 
protective action in the public domain were tested during the recently conducted off-site emergency exercise at NPP site with the following objectives (a) To facilitate the decision making on GIS platform in public domain around NPP site during nuclear emergency (b) To predict the radioactive doses due to exposure pathways like plume dose, ground shine dose, inhalation dose and ingestion for the urgent phase of the accident (a few days) based on real time observations and meteorological forecasts (c) To predict optimized protective actions/strategy in emergency management to minimize the radiological consequences in public domain.

\section{A. ONERS - Decision Support System}

The ONERS decision support system developed [1] by IGCAR is an indigenously developed GIS based spatial DSS with comprehensive tools for prediction and projection of radionuclide doses in both short and long-ranges. The system computes the radionuclide dispersion using the Lagrangian Particle dispersion model (FLEXPART). The system uses onsite meteorological observations in the short-range (15 $\mathrm{km}$ ) and predictions by high resolution numerical weather forecast model (WRF) in the long-range $(100-\mathrm{km})$ for estimation of dispersion and radio-nuclide dose projection. The weather forecast model WRF was configured to provide high resolution meteorological predictions for all 7 operational nuclear power plant sites of India. The outer domain at $18-\mathrm{km}$ resolution covers India and neighbouring ocean areas, the intermediate domain with $6-\mathrm{km}$ resolution covers Indian landmass and the innermost domains at 2-km resolution cover different NPP stations. The dispersion calculations are done with FLEXPART using a concentration grid resolution of $1-\mathrm{km}$ for the long range projections and using 200-m resolution grid for short-range real time estimates. ONERS has several modules like source term, meteorological predictions, countermeasures, infrastructure identification, simulation of hourly and time integrated doses, counter measure evaluation etc. The models were validated using national meteorological observations, field experiments and routine reactor releases. The ONERS system was used to analyze the radiological impact during the off-site emergency exercise conducted at NPP site. Radiological dose and Iodine concentrations were estimated in the offsite area around NPP for the postulated accident scenario. The system could represent the wind field patterns around the site. The dose projections given by ONERS show spatial variation in the radiation field. Using DSS the radiological impact could be spatially visualized on various maps in terms of emergency zones and distances. Secondly the information on likely dose in various villages could be generated to facilitate the decision makers and response organizations for planning the protective actions. The utility of the ONERS in the exercise demonstrated its potential application in management of nuclear / radiological emergencies.

\section{B. Real Time Online Decision Support System (RO_DSS)}

Real time online decision support system (RO_DSS) for nuclear emergency was customized by NPCIL based on the Indian real time online decision support system (IRDOS) developed [2] by the BARC. The system uses site specific real time meteorological data and radiological conditions around the plant monitored by on-line environmental radiation monitors. The system uses Gaussian puff model RIMPUFF which takes care of inhomogeneity in time and space and potential source term based on accident scenario. The countermeasure module estimates projected dose, averted dose and residual dose. The model also gives post-accident ground shine dose from the deposited activity for different periods. The output generated by the system is used to facilitate the decision making on GIS platform in public domain, predict the radioactive doses due to exposure pathways like plume dose, ground shine dose and inhalation dose in real time \& forecast. The model also predicts optimum protective actions that are required to be taken for minimizing the radiological consequences in nuclear emergency.

The RO_DSS provides the estimation of instantaneous concentration, time integrated concentration, ground deposition, plume shine and ground shine doses, Inhalation dose and Thyroid dose on predictive as well as real time basis. In the predictive mode, it uses 72 hours forecasted NWP, predicts the consequences for next 48 hours with hourly resolution and updates every 24 hours. In real time mode, it uses the hourly online data received from ESLs meteorological station and predicts the consequences for the next hour. On the basis of projected dose, affected areas are identified for decision making on implementation of protective actions that includes administration of stable iodine tablets, sheltering, evacuation, food control and decontamination either individually or in combination for optimization. Thus RO_DSS facilitates emergency managers as a real-time decision aid during nuclear emergency. The protective actions can be implemented by emergency managers in advance to avert the dose to the public and minimize the radiological impact.

\section{Dose Projection and Atmospheric Dispersion Model}

The dose projection and atmospheric dispersion model developed by the SRI, AERB was employed to study the environmental impact assessment of hypothetical accident scenario during the emergency exercise at Nuclear Power Plant (NPP). The model used calculated source term for given hypothetical accident scenario for different radionuclides and Numerical Weather Prediction (NWP) Model, Weather Research and Forecasting (WRF) coupled with Lagrangian particle model FLEXPART for the dispersion studies. For the present study, a parent domain of grid dimension $18 \mathrm{~km} \times 18 \mathrm{~km}$ was selected with two inner nested domains with grid dimensions, $6 \mathrm{~km} \times 6 \mathrm{~km}$, and $2 \mathrm{~km}$ $\mathrm{x} 2 \mathrm{~km}$. The outer domain covers most of central India with the innermost domain covering the Rawatbhata RAPS site. The model domains were centered at $24.87 \mathrm{~N}$ and $75.62 \mathrm{E}$. The surface wind patterns were studied for wind direction and identification of the affected sector. The projection of likely

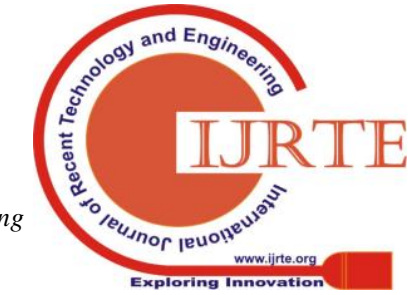




\section{Application of Decision Support System during the Emergency Exercises for Nuclear Emergency Management}

radiation doses in the public domain and major contributing radionuclide were generated by model. These dose estimates were used by decision makers for implementation of the protective actions.

\section{ACCIDENT RADIOACTIVE SOURCE TERMS}

The assessment of source term was independently done by RO-DSS (NPCIL) and safety analysis group (SAG, AERB). The potential source term was evaluated by RO-DSS based on accident scenario assessment and from the potential source term files (for ground level \& elevated release) for several hypothetical beyond design basis accidents (BDBA) scenarios available in RO_DSS.
SAG evaluated the source term based on regulatory guidelines and accident scenario parameters received from exercise NPP site. The hypothetical accident scenario considered was loss of coolant accident (LOCA) + loss of emergency core cooling system (LECCS) + failure of moderator cooling system + containment breach for the source term assessment. The estimated accident source term was specified in the ONERS and DSS for dose projections. The initial isotopic core inventory was considered for the source term estimation. The cumulative release quantities of fission product noble gases (FPNG) and volatiles / particulates up to 12 hours of accident progression were as given in Table 1.

Table- I: Cumulative radioactivity release quantities in a hypothetical accident

\begin{tabular}{|c|c|c|c|c|c|}
\hline Time $(\mathrm{h})$ & Volatiles $(\mathrm{Bq})$ & FPNG $(\mathrm{Bq})$ & Time $(\mathrm{h})$ & Volatiles $(\mathrm{Bq})$ & FPNG $(\mathrm{Bq})$ \\
\hline 2 & $2.27524 \mathrm{E}+14$ & $1.62 \mathrm{E}+16$ & 8 & $3.73148 \mathrm{E}+15$ & $1.07 \mathrm{E}+18$ \\
\hline 3 & $2.52757 \mathrm{E}+15$ & $5.41 \mathrm{E}+17$ & 9 & $3.76434 \mathrm{E}+15$ & $1.10 \mathrm{E}+18$ \\
\hline 4 & $3.25314 \mathrm{E}+15$ & $7.83 \mathrm{E}+17$ & 10 & $3.79042 \mathrm{E}+15$ & $1.14 \mathrm{E}+18$ \\
\hline 5 & $3.51051 \mathrm{E}+15$ & $9.03 \mathrm{E}+17$ & 11 & $3.8121 \mathrm{E}+15$ & $1.16 \mathrm{E}+18$ \\
\hline 6 & $3.62335 \mathrm{E}+15$ & $9.74 \mathrm{E}+17$ & 12 & $3.8282 \mathrm{E}+15$ & $1.19 \mathrm{E}+18$ \\
\hline 7 & $3.6878 \mathrm{E}+15$ & $1.03 \mathrm{E}+18$ & 13 & $3.84126 \mathrm{E}+15$ & $1.21 \mathrm{E}+18$ \\
\hline
\end{tabular}

\section{METEOROLOGICAL AND DISPERSION PREDICTIONS}

\section{A. Predictions by ONERS-Decision Support System}

The operational Numerical Weather Predictions for the NPP sites at IGCAR are used for the Emergency Exercise of RAPS.

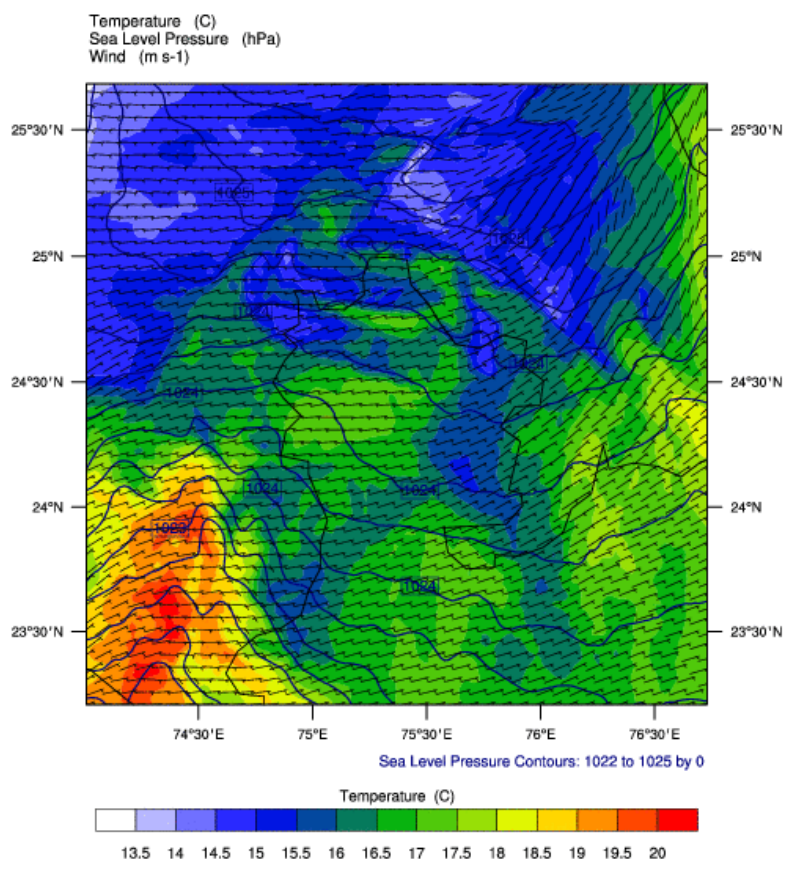

(a)

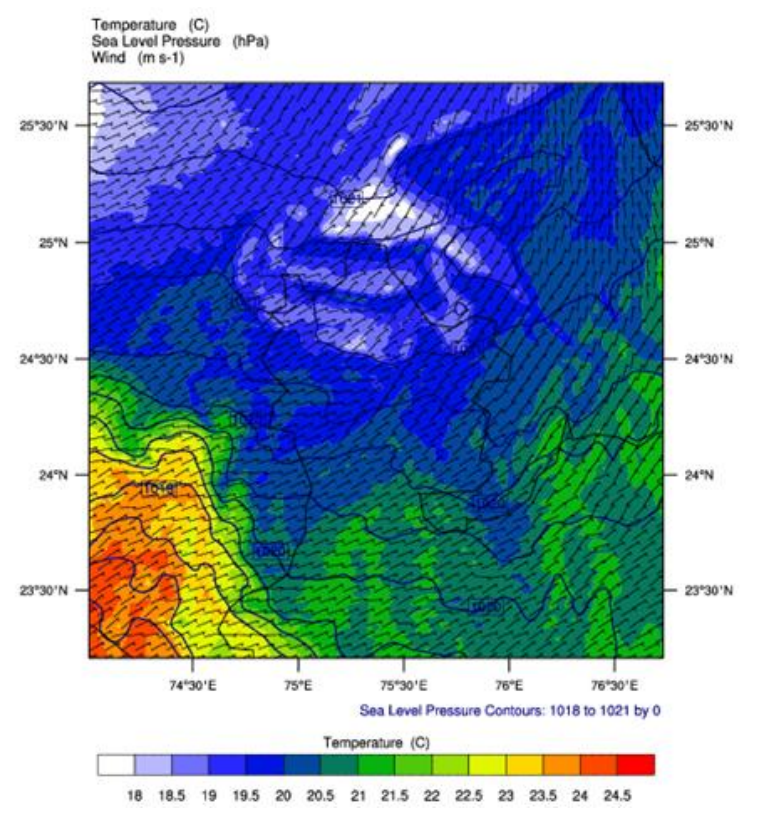

(b)

Fig. 1.Predicted flowfield, temperature and surface pressure pattern on 15 Dec 2018 (a) for 1030 IST (b) for 1530 IST

The model horizontal grid resolution is $2-\mathrm{km}$ and has 36 vertical layers. The numerical weather prediction (NWP) modeling system (WRF) is run with the NCEP Global Forecasting System (GFS) $0.5 \times 0.5 \mathrm{~km}$ analysis and forecasts and the model is integrated up to 72 hours starting from 00 UTC/0530 IST.

The forecasts of boundary layer flow-field, the surface level temperature and humidity in a domain of $200 \mathrm{~km} \mathrm{x} 200 \mathrm{~km}$ around RAPS site are shown in

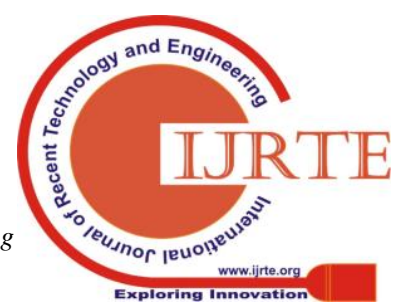


fig. 1 at two times (1030 IST, 1530 IST). The forecast of mixed layer height was also done. The dispersion of atmospheric releases over the Rawatbhatta Site was simulated using the Lagrangian particle dispersion model FLEXPART which was configured with $100 \mathrm{x} 100$ concentration grids each of $1-\mathrm{km}$ horizontal levels and 10 vertical levels in the $3000 \mathrm{~m}$ lower atmosphere. The dispersion / deposition calculations are made for $1 \mathrm{~Bq} / \mathrm{s}$ for Volatiles and Noble gases separately and the outputs are used in the dose modules to compute the dose through various pathways considering the release fractions of various radio-nuclides. The radionulide doses in DSS are scaled as per actual release quantities and release duration. The flow-field around the NPP station is spatially heterogenous. The ONERS forecasts showed easterly windflow (wind blowing from the east) over Rawatbhatta in the morning time till 1030 IST. The forecasts indicated the flow directions subsequently changed as East North East /East. The average wind speed was about $4.0 \mathrm{~m} / \mathrm{s}$, air temperature varied as 15 ${ }^{\circ} \mathrm{C}$ in the morning to $20{ }^{\circ} \mathrm{C}$ in the daytime. Stable atmospheric conditions (Paquill cateogory -E) prevailed in the morning followed by neutrally stable (Pasquill Category-D) conditions in the daytime. The mixed layer height was $400 \mathrm{~m}$ in the morning and the layer gradually deepened to $1000 \mathrm{~m}$ in the daytime.

\section{B. Predictions by Real time Online Decision Support System (RO_DSS)}

The system was operated in two modes. In the predictive mode, system used 72 hours forecasted NWP data for predicting the radiological consequences for next 48 hours with hourly resolution for larger area beyond the NPP site. In real time mode, system used the hourly online data received from ESLs meteorological station of NPP and predicted the radiological consequences near the NPP site for the next hour for higher accuracy.

\section{Predictions by Dose Projection Model / Atmospheric Dispersion Model at SRI-AERB}

Dispersion simulations were carried out over a $45 \mathrm{~km}$ x 45 $\mathrm{km}$ model domain having $100 \times 100$ grid points with a grid resolution of $\sim 450 \mathrm{~m}$.

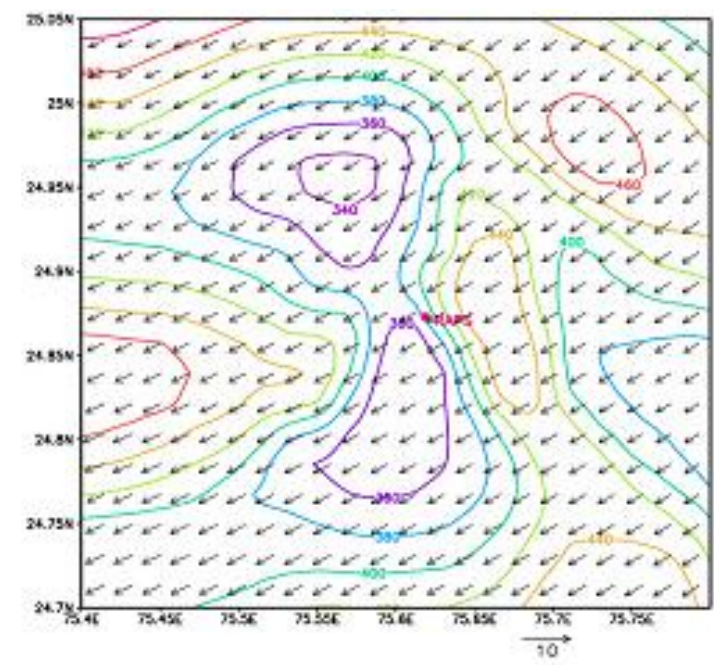

(a)

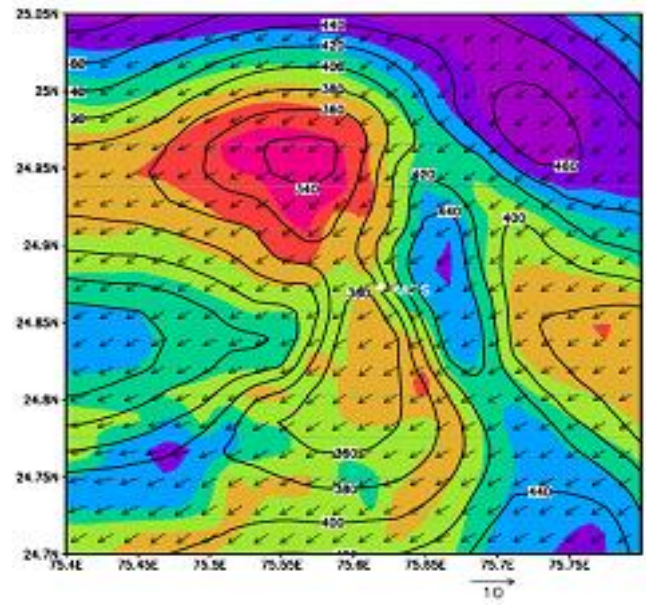

(b)

Fig. 2. (a) Topography of the RAPS site (contour) and the horizontal winds at $925 \mathrm{hPa}$ pressure level (b) Surface winds $(10 \mathrm{~m}), 2 \mathrm{~m}$ temperature (shaded contour) and topography over the $2 \mathrm{~km}$ WRF model domain

A total of 8 vertical layers were considered and 160000 pseudo particles were released. Particles were sampled every $5 \mathrm{~s}$ and averaged over $3600 \mathrm{~s}$ to obtain the average concentration and then the radiation doses for various exposure pathways. The turbulent diffusion was modelled using the Hanna semi-empirical scheme. Meteorological parameters obtained from WRF simulation was used for running the dispersion model. The topography of the RAPS site (contour) and the horizontal winds at $925 \mathrm{hPa}$ pressure level obtained by the model are shown in Fig. 2.

\section{DOSE PROJECTIONS USING DECISION SUPPORT SYSTEM}

\section{A. Dose Predictions Using the ONERS-DSS}

In ONERS, the cumulative release values for FPNG and Volatiles and the corresponding release duration was given as input. The start time of the release was taken as 10:30 IST, the exercise start time. The hypothetical accident gradually progressed to LOCA + ECCS Failure + Containment leakage with FPNG activity release $1.22 \mathrm{E}+18 \mathrm{~Bq}$ and Volatiles activity release $3.85 \mathrm{E}+15 \mathrm{~Bq}$ for the release duration 12-hours. The present calculation used the cumulative value at 12 hours to examine the maximum possible doses in public domain around the RAPS for this event. The ONERS calculated cumulative Effective dose for the 12-h release period is presented in Fig.3. The projected dose for $12 \mathrm{~h}$ release period indicated that though the plume direction is not changed, the plume is spread over a wider area during the $12-\mathrm{h}$ period covering more villages under its influence. Also the spatial dose field up to $30-\mathrm{km}$ increased with progression of accident scenario. The projected dose value at the exclusion zone boundary was $9.0 \mathrm{mSv}$ which reduced to 1.5 $\mathrm{mSv}$ at $5-\mathrm{km}$ distance, $0.5 \mathrm{mSv}(50 \mathrm{mR})$ at $16-\mathrm{km}$ and further reduced to $0.05 \mathrm{mSv}(5 \mathrm{mR})$ at $30-\mathrm{km}$. The projected cumulative thyroid dose and iodine concentration were also evaluated using the DSS.

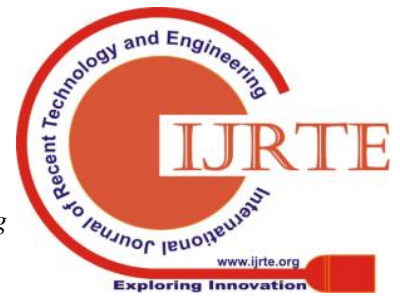




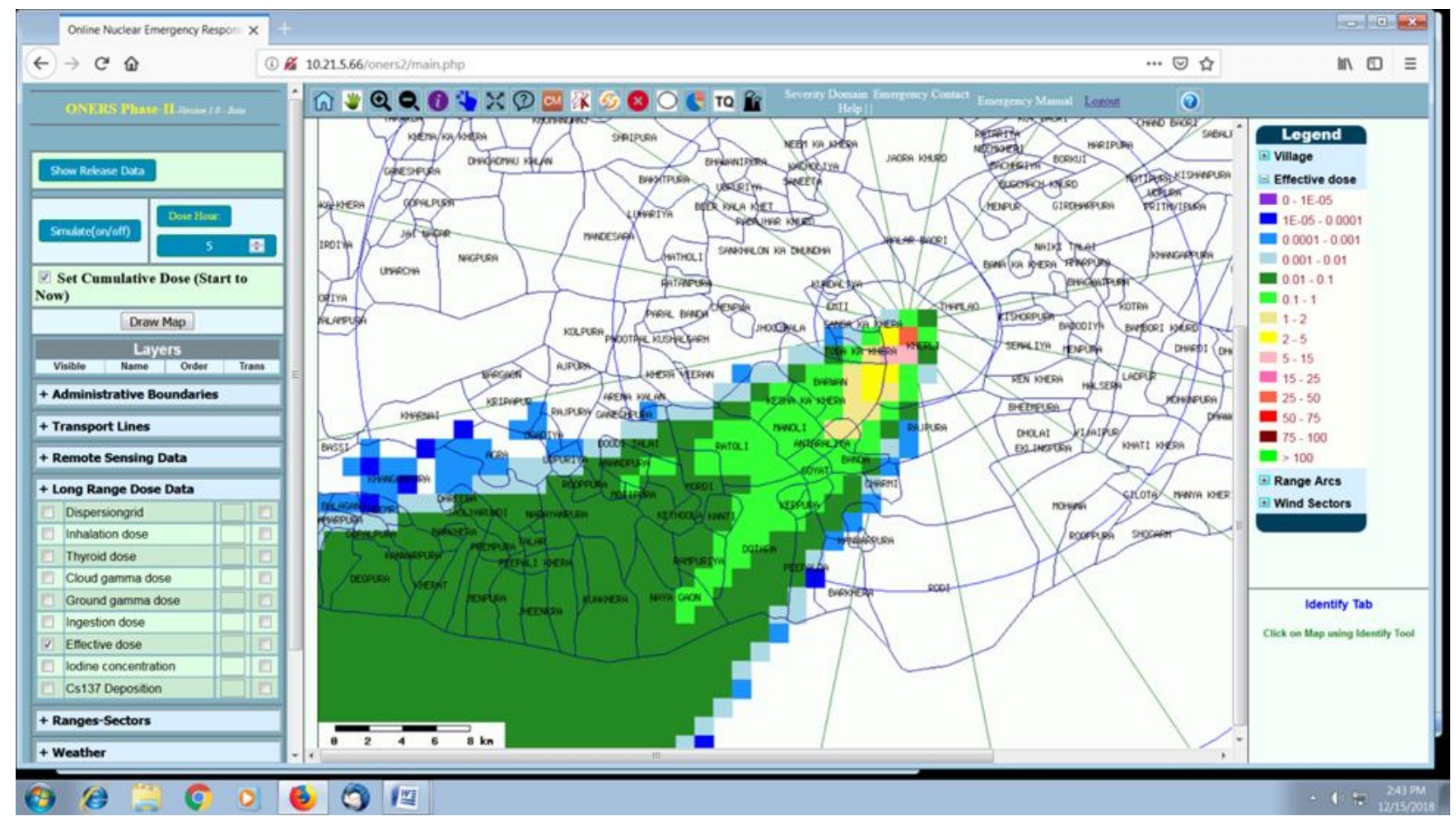

Fig. 3. Cumulative whole body dose $(\mathrm{mSv})$ for the LOCA + ECCS + Containment EP Failure for 12-h release

\section{B. Dose Predictions Using Real Time Online Decision Support System (RO_DSS)}

RIMPUFF code in RO_DSS was used for estimation of instantaneous concentration, time integrated concentration, ground deposition, plume shine and ground shine doses, inhalation dose and thyroid dose on predictive as well as real time basis. The regulatory criteria of $50 \mathrm{mSv}$ in 7 days projected thyroid dose and $100 \mathrm{mSv}$ in 7 days projected whole body dose was used for identification for affected area and implementation of protective actions.

\section{Dose Projection Model / Atmospheric Dispersion Model}

The system used Lagrangian particle model FLEXPART for the dose assessment using the forecasted weather parameters. Total dose due to I-131 and that due all other important radionuclide was studied, for all exposure pathways (inhalation, dose due to ground deposited activity, external gamma dose) for the first 7 days of accident progression. The distribution of thyroid dose in public domain due to the inhalation of I-131 was estimated. At the site boundary (1.5 km from the NPP) thyroid dose $>50 \mathrm{mSv}$ was observed and at $5 \mathrm{~km}$, along the plume direction the thyroid dose for general public was estimated as $10 \mathrm{mSv}$.

\section{RECOMMENDATION FOR IMPLEMENTATION OF PROTECTIVE ACTIONS BY DDMA}

Based on the simulations from the DSS, the affected zone and distances were identified for the protective actions in the public domain to control the radiological impact. This forms the important part of the emergency management. The implementation of protective actions (early warning, access control, Iodine thyroid blocking, sheltering and prevention of consumption of open food) in the affected villages was ordered by the district disaster management authority from emergency operating centre (EOC). The local administration and various emergency response teams physical visited affected villages and noted down the response times for the completion of protective actions.

\section{RESULT AND DISCUSSION}

Three decision support systems (DSS) were tested during the exercise at RAPS NPP. The weather forecasting and dose projection results were used by the site emergency director (SED), ERD (CMG-DAE) and district authorities (DDMA) for the decision on protective actions in the public domain. Protective Actions Recommendations (PAR) was issued initially by SED based on DSS information and subsequently by ERD based on DSS and environmental radiological survey results.

The ONERS could project the increase in the dose values with the progression of the accident as per the source term variation with time. Radiological dose and Iodine concentrations were estimated in the off-site domain for a postulated accident LOCA + ECCS + Containment EP failure for a release period of 12-hours. The dose projections were based on uniform release rate for FPNG and Volatiles considering the total release quantity and the release duration. Nevertheless the system could project the radiation dose profile realistically by showing the plume impact areas over the village maps and the affected sectors (emergency planning zones and distances).

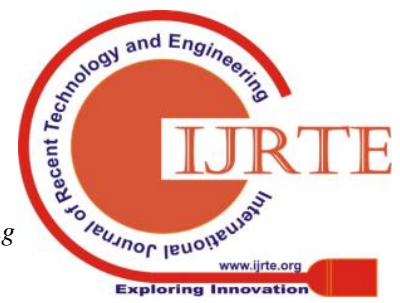


This helped emergency managers to arrive at suitable decisions like where the protective actions need to be implemented and the time of initiating such actions in public domain. The accident source term consisted of about 82 radionuclides. For the purpose of dose projections during emergencies it is required to narrow down to a few important radionuclide species which have high energies and long-half life to quickly estimate the doses. The time varying source term was not used during the exercise. The feature of time-varying source term release data for various kinds of accidents scenarios can be incorporated in the ONERS.

RO_DSS with RIMPUFF code was used for estimation of instantaneous radionuclide concentration, time integrated concentration, ground deposition, plume shine and ground shine doses, Inhalation dose and Thyroid dose on predictive as well as real time basis. In the predictive mode, 48 hour radiological consequences were forecasted. In real time mode, it used hourly online data received from ESLs meteorological station and predicted the consequences for the next 1 hour. On the basis of projected dose, affected areas was identified for decision making on implementation of protective actions that includes administration of stable iodine tablets, sheltering, evacuation and food control. Thus RO_DSS facilitated emergency managers as a real-time decision aid during nuclear emergency. The protective actions and effected zone could be identified by emergency managers in advance to avert the dose to the public and minimize the radiological impact.

The dose projection and atmospheric dispersion model used WRF and FLEXPART for 72 hours simulations for RAPS exercise site. The winds over the site were north-easterly or east-northeasterly during the simulation period. During the radioactivity release period the average surface wind speed observed at the release point was $5 \mathrm{~m} / \mathrm{s}$. however, in the night, a temperature gradient was developed across the land and nearby water bodies, which resulted in relatively strong winds with wind speed $5-7 \mathrm{~m} / \mathrm{s}$ at the release point. FLEXPART simulation for dose projections was carried out for 48 hours from the start of the exercise. The release was assumed to be initiated at 07:00 UTC (12:30 IST) i.e. start of the exercise on $15^{\text {th }}$ December and continued for 30 hours. FLEXPART simulations showed that, due to north-easterly winds, the radionuclide plume was carried towards the southwest direction and the southwest sector was found to be the most affected sector. Out of the five radionuclide studied, I-131 was found to be the major contributor to the radiation dose. In the immediate vicinity of the NNP site, thyroid dose due to the inhalation of I-131 was estimated. At the NPP site boundary (1.5 km from the NPP) thyroid dose in excess of $50 \mathrm{mSv}$ was observed.

The results on projected dose, effected area and protective action in public domain by using three DSS were comparable and consistent taking into account the high uncertainties in the source term estimation and inputs to the simulation models. The study demonstrated the flexibility of DSS systems for the assessment of the radiological consequences and its application in the nuclear emergency management.

\section{CONCLUSION}

Three decision support systems (DSS) developed by IGCAR (ONERS-Decision Support System), NPCIL (Real time Online Decision Support System (RO_DSS)) and SRI-AERB (Dose projection model / Atmospheric dispersion model) were tested during recently conducted off-site emergency exercise at RAPS site in December 2018. These three DSS were used independently for weather predictions, generate meteorological parameters, atmospheric dispersion, dose projections, identification of emergency zones and distances and decision on the implementation of the protective action in the public domain. All the stake holders including plant management, district authorities, NPCIL HQ, CMG-DAE, NDRF of MHA, AERB, NDMA and state authorities participated in the exercise to test their decision making process, effective coordination, identification and implementation of protective actions.

The hypothetical accident scenario involving loss of coolant accident (LOCA), loss of emergency core cooling (ECCS), loss of moderator cooling and containment leakage was considered for the exercise. The radioactive source term was estimated independently by two methods based on plant parameters and pre calculated source term for large number of accident scenarios was used during the exercise. The results of the assessments by using these decision support systems were presented to the decision makers for recommendation and implementation of protective actions such as evacuation, sheltering, KIO3 distribution, contamination control etc. The Numerical Weather Forecast model was used for the area around the NPP to produce the meteorological parameters that were further used by these DSS systems. A predictive assessment of the radiological situation in the vicinity of the NPP site was performed with various source terms. Taking into account the high uncertainties in the source term estimation and inputs to the simulation models, the simulated results from these three DSS show a reasonable agreement. The study demonstrated the flexibility of DSS systems for the assessment of the radiological consequences of hypothetical nuclear accidents during the emergency exercise at NPP site and its application in the nuclear emergency management. The experience gained in using the DSS systems for operational application to the Indian NPP will be further used by the exercise planners and developer to improve the system continuously and their adaptation to all NPP sites in India.

\section{ACKNOWLEDGMENT}

Authors are grateful to Shri R. M. Godbole, Station Director, RAPS $3 \& 4$ (NPCIL) for the guidance and support in preparing this paper. We are also grateful to Shri $\mathrm{R}$. Bhaskaran, AD, RESG, HSEG, IGCAR and Shri J. Koley, Head, Directorate of Radiation Protection and Environment (AERB) for their keen interest, valuable suggestions and useful comments during the entire course of this work. The authors also greatly appreciate the active cooperation and assistance of their colleagues from AERB, IGCAR and NPCIL. 


\section{REFERENCES}

1. S. S. Raja Shekahr, Shantanu Bhatawadekar, Dr. Y.V.N. Krishna Murthy, Dr. C.V. Srinivas and Dr. Venkatesan, "Development of a Online Nuclear Emergency Response System (ONERS) for Kalpakkam site - The design aspects", Proceedings NSRP-19, Dec.12-14, 2012.

2. Vinodkumar A., Oza R.B., Nair C.K.G., Awasthi A., Ratheesh M.P., Chaudhuri P., Suri M.M.K., Saindane S., Singh K.D., Bhargava P., Anand S., Sharma V.K., "Indian Real Time Online Decision Support (IRODOS)", BARC News Letter, Issue 2, May 2008.

\section{AUTHORS PROFILE}

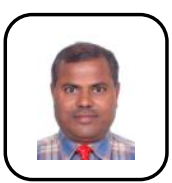

First Author Shri Shivaji K. Pawar, a graduate in Physics from Shivaji University Kolhapur, Post graduate in Pulp and Paper Technology, Roorkhee University (IIT, Roorkhe), AMIE (Chemical Engineering) from The Institution of Engineers (India), Kolkotta and MBA (HRM) from IGNOU, New Delhi. He joined Health Physics Division, Bhabha Atomic Research Centre, Mumbai in the year 1988. With professional carrier spanning over 31 years at Nuclear Power Plants and Atomic Energy Regulatory Board, He has specialised in the area of Operational Health Physics, Regulatory Aspect of Radiological Safety and Emergency Preparedness. He has commissioned radioactivity counting instruments, radiation monitoring instruments, radiation instrument calibration facility, dose management systems, effluent radioactivity monitoring systems and standardized radiological monitoring procedures, dose monitoring, radioactivity monitoring, radiation protection procedures and emergency management systems at NPPs. He has over twenty three years of experience in operational health physics at NPPs and BARC Tarapur facilities and implemented radiation protection programme very effectively. He was Senior Health Physicist at NAPS (Narora), Head Health Physics Unit at TAPS-3\&4 first 540 MWe PHWR (Tarapur) and Head, Health Physics Lab, BARC (Tarapur). He is recipient of the Meritorious Operational Health Physicist of Indian Association of Radiation Protection. Shri Shivaji. K. Pawar joined Atomic Energy Regulatory Board in 2010 and since then he is associated with regulatory review of radiological safety and emergency preparedness of NPPs and fuel cycle facilities. He has developed regulatory documents related with radiological safety \& Nuclear Emergency Management and contributed in the development of Indian standards and ISO standards on Radiological protection. He was invited speaker and faculty member for training courses on radiological safety and emergency preparedness. He has over 50 publications in national and international journals and over 30 presentations during the national and international conferences and workshops. He participated in IAEA/ConvEx emergency exercises, IAEA technical meetings, WANO peer reviews, IAEA/RCA field trials on emergency response capacity and IAEA/RCA regional training workshop on ICRP recommendations and IAEA standards. He led Indian delegation for ISO/TC-85/SC-2 meetings held at Niagara Falls (Canada) and Worcester (USA) and participated in these meetings held at Moscow (Russia) and New Delhi (India). He is Member of Indian Association of Radiation Protection, Indian Nuclear Society, ISO/TC-85/SC-2 (Working Groups) on radiation protection and Co-convenor of BIS/CHD-30 subcommittee on radiological protection. Presently, he is Scientific Officer (G) and Head, Health Physics and Emergency Preparedness Section, Directorate of Radiation Protection and Environment, Atomic Energy Regulatory Board, India.

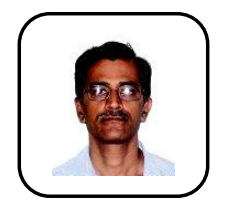

Second Author Dr. C.Venkata Srinivas is borne on August 15, 1965. He has received Master's degree in Meteorology in the year 1989 from Andhra University and Master's degree in Physics in 1996 from Annamalai University. He was awarded Ph.D in Meteorology from Andhra University for "Studies on Land-Atmosphere Biosphere interactions using Remote Sensing Methods with special reference to different climate zones of Maharashtra" in 2001. He is working as Scientific Officer/G at the Department of Atomic Energy, Indira Gandhi Centre for Atomic Research, Kalpakkam. Presently he is the Head, Radiological Impact Assessment Section in Radiological and Environmental Safety Division, Safety Quality and Resource Management Group, IGCAR Kalpakkam. He is specialized in Atmospheric Science, Atmospheric Dispersion modeling, Nuclear Emergency Response Decision Support Systems, Radiological Impact Assessment studies, Numerical weather prediction, modelling of Air Quality, Aquatic dispersion and Aerosol studies. He has contributed significantly in the development of on line Nuclear Emergency Response System (ONERS). This system is regularly used during the emergency exercises at NPPs. He has received Group Achievement Award in the year 2017 by DAE. He has published several research papers in national and international Journals, presented papers in national and international conferences and also participated in workshops and seminars.

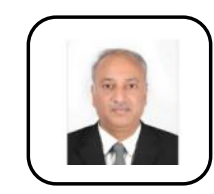

Third Author Dr. B.Venkatraman, a post graduate in Physics from St. Joseph's College (Autonomous), Trichy and Doctorate in Physics-NDE from Madras University joined the 27th batch of training school of Bhabha Atomic Research Centre, Mumbai in 1983 and after successful completion of the training, joined Indira Gandhi Centre for Atomic Research (IGCAR), Kalpakkam in Aug. 1984. With a research career spanning 34 years, he has specialized in the areas of Non-Destructive Evaluation, Radiation sciences, its applications and quality assurance. During the last decade, he has focussed on radiological surveillance and protection for all the radioactive and non active facilities at IGCAR, implementation of Online Decision Support System for Radiological Emergency at Kalpakkam site and enhancement of facilities for radiological emergency response and streamlining procedures. He has over 300 publications in peer reviewed international journals and conferences including two articles in Encyclopedia of Material Science, two monographs, one book Chapter and is the series editor for the NDT handbooks published by National Certification Board, ISNT. He is the recipient of D \& H Schereon Award of IIW 1993, ISNT-NDT Man of the Year Award (R \& D) 2001, INS Gold Medal 2005, DAE Homi Bhabha Science and Technology Award 2007, IIW Sharp Tools Award 2011, ISNT international recognition award 2013, and has won more than 10 best paper awards. He is the Honorary Fellow of Indian Society of NDT and Fellow Chennai Academy of Sciences $\mathrm{He}$ is the President of Indian Association for Radiation Protection, President Elect Indian Society for NDT, Board Member, Asian Pacific Federation of NDT, Convenor Bureau of Indian Standard (BIS) CHD 30 Sub Committee on Radiation Protection. He was a visiting scientist and Fraunhofer Institute of NDT Saarbrucken during 2006-2007 and has been invited to deliver plenary, keynote and invited talks in many international conferences abroad. Presently, he is the Director, Safety Quality and Resource Management Group, IGCAR Kalpakkam.

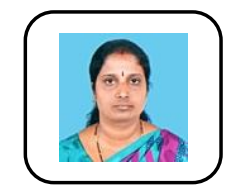

Fourth Author Dr. J. Bhavani, is born on June $7^{\text {th }}$ 1982. She has received her master degree in business administration in the year 2004 from Thanthai Hans Reover College, and master of philosophy in business administration in the year 2006 at Bharathidasan University, Trichy. She was awarded the doctorate degree on "Impact of Labour Welfare Measures on Industrial Relations" with reference to Private Sugar Mills in Tamilnadu at Sathyabama University, in the year 2013. She has secured first class in all her academic achievements with distinctions in many subjects. She is specialized in Human Resource Management and possesses teaching experience of fifteen years. She currently works as an Assistant Professor, Business School, Vellore Institute of Technology, Chennai. She has received BEST FACULTY award in the year 2014, by the Nehru Group of Educational Institutions out of 432 applicants. She has published many research papers in journals, presented papers in conferences and also participated in workshops and seminars both national and international level. 